\title{
Uma sequência didática para abordagem do tema lixo eletrônico no ensino de Química
}

\section{Cláudia Thamires da Silva Alves ${ }^{1}$, Josinaide Guerra de Santana Cavalcanti ${ }^{2}$, José Euzébio Simões Neto ${ }^{3}$}

\author{
${ }^{1}$ Licenciada em Química pela Universidade Federal Rural de Pernambuco. \\ ${ }^{2}$ Licencianda em Química pela Universidade Federal Rural de Pernambuco. \\ ${ }^{3}$ Doutor em Ensino das Ciências pela Universidade Federal Rural de Pernambuco. \\ Professor da Universidade Federal Rural de Pernambuco (UFRPE/Brasil).
}

\section{A didactic sequence to approach the electronic waste subject in chemistry teaching}

\section{Informações do Artigo}

Recebido: 30/03/2018

Aceito: $16 / 06 / 2018$

Palavras chave:

Lixo eletrônico, Abordagem CTS,

Ensino de Química.

E-mail:

claudiaa.tsalves@gmail.com

\begin{abstract}
A B S T R A C T
The aim of this study was to propose a teaching learning sequence to approach the e-waste issue in high school. For that, we structured the sequence entitled "Electronic waste and its social and environmental implications", in five moments: presentation of the social problem, conception survey, presentation of the structuring chemical concepts from a dialogic expositive class and two moments to solve problems, one focused on the disposal of electronic waste and another on the ideas of obsolescence and recycling. We sought the validation of the proposal from the application in a class of the Second Year of High School of a federal technical school, located in Camaragibe, Pernambuco. The results point to the validation of the proposal, especially the suggestion of the use of selective collection of litter and potatoes at school, however, the students showed difficulties in understanding the idea of electronic waste obsolescence.
\end{abstract}

\section{INTRODUÇÃO}

As tecnologias estão cada vez mais presentes em nossas atividades diárias, das mais simples até as mais complexas, e praticamente não realizamos nenhuma ação no dia sem que tenhamos utilizado alguma tecnologia eletrônica - acordamos e desligamos o condicionador de ar ou ventilador, tomamos banho em chuveiros quentes, olhamos o horário do ônibus no aplicativo do celular, utilizamos computadores e tablets no trabalho, entre outras ações, todas elas com aparelhos eletrônicos que facilitam nossas tarefas. A velocidade da inovação tecnológica é tal que em pouco tempo nossos aparelhos eletrônicos já são considerados ultrapassados, mesmo atendendo nossas demandas e funcionando corretamente, e somos induzidos a trocá-los por versões mais atuais. E é aí que surge um 


\section{Educação Química}

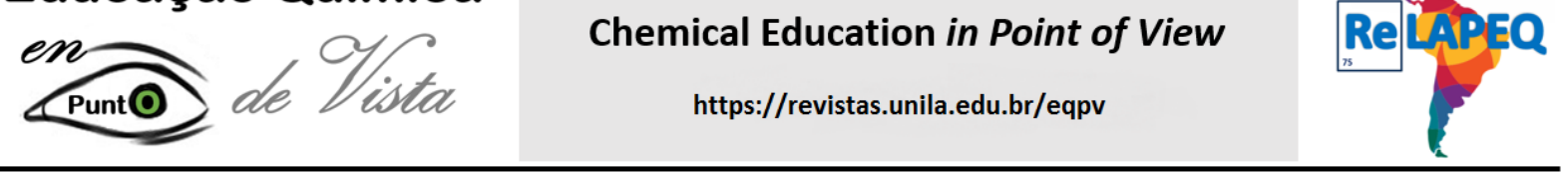

grande problema: o mercado de equipamentos eletrônicos usados não cresce na mesma proporção do descarte e a busca pelo novo, pelo recém-lançado, pelo mais moderno, é uma tônica no mundo capitalista em que vivemos (PARENTE, 2007). Ou seja, a cultura do consumo desenfreado de equipamentos eletrônicos é um dos problemas socioambientais desse início de século e afeta o meio ambiente em duas frentes: de um lado temos a produção de novos aparatos tecnológicos, que exige elevada quantidade de recursos naturais, tais como matéria prima, água, energia e combustíveis; do outro, devido as constantes substituições e atualizações, o descarte indevido de equipamentos eletroeletrônicos, que geralmente são levados para lixões ou aterros sanitários como resíduos urbanos comuns.

Podemos definir lixo eletrônico como todo resíduo resultante da rápida obsolescência de equipamentos eletroeletrônicos, incluindo aparelhos compostos quase que totalmente por circuitos eletrônicos (televisores, celulares, computadores, aparelhos de som) e equipamentos eletrodomésticos que possuem alguma parte eletroeletrônica, como geladeiras, máquinas de lavar, fornos micro-ondas e batedeiras (FAVERA, 2008). Esse tipo de lixo está diretamente associado a diversos problemas socioambientais, pois podem poluir solos e lençóis de água, além de liberar substâncias tóxicas na atmosfera, se queimados. Trata-se de um tema que envolve ciência, tecnologia e a sociedade, além do meio ambiente e, por isso, parece ter potencial para ser trabalhado na abordagem CTS (Ciência - Tecnologia - Sociedade), que busca, a partir da relação entre esses três elementos, desenvolver o pensamento crítico e a tomada de decisão, além de reflexão sobre as consequências das nossas escolhas e ações para a sociedade e o meio ambiente.

Então, a abordagem CTS pode ser entendida como uma proposta didática, iniciada na década de 1960, como uma forma de se compreender as inter-relações entre ciência, tecnologia e a sociedade (SANTOS; SCHNETZLER, 1997), levando em consideração o ambiente em que vivemos, com o objetivo de formar cidadãos capazes de utilizar os conhecimentos científicos para argumentarem de maneira crítica sobre as limitações e implicações do desenvolvimento científico e tecnológico na organização social e no ambiente em que estão inseridos, para julgar e avaliar as possibilidades (FIRME; AMARAL, 2011).

Santos e Nunes (2016) apontam que, desde a sua origem, os estudos envolvendo a abordagem CTS, dentro e fora da sala de aula, apresentam uma perspectiva de reflexão, alicerçadas por insatisfações expressas pelos movimentos sociais, que buscavam uma visão de ciência mais adequada a sociedade, indo além de uma perspectiva positivista dominante.

Assim, entendemos que o trabalho em sala de aula que considera como perspectiva a abordagem CTS possibilita um enfoque para além das questões puramente relacionadas a conhecimentos científicos específicos, utilizados em contextos tradicionais para a resolução de exercícios inspirados no trabalho laboratorial do cientista. Para Costa e Silva (2013), essa 


\section{Educação Química}

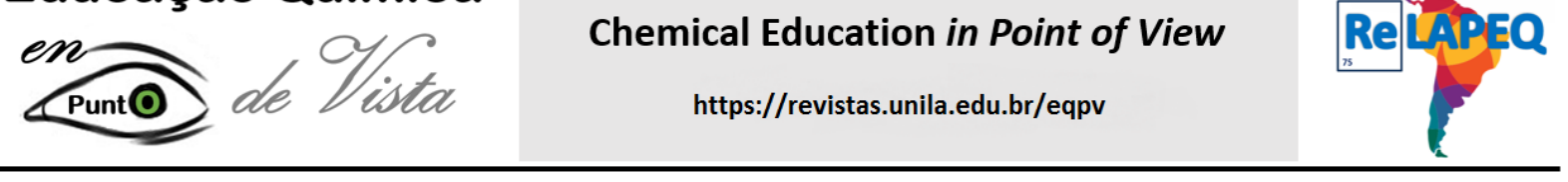

abordagem implica em considerar outras áreas de conhecimento no ensino das ciências, com ênfase em questões históricas, epistemológicas e sociais, que estarão relacionadas com o processo evolutivo da ciência e da tecnologia, os limites dos enunciados científicos, os impactos sociais e ambientais.

Concordamos com Silva e Amaral (2013) quando afirmam que trabalhar o ensino numa abordagem CTS se faz mediante o rompimento com uma abordagem baseada no ensino tradicional, centrado na transmissão das informações científicas, sem nenhuma preocupação com a realidade social e ambiental dos estudantes. Ou seja, a escola deve estar preparada para a missão de formar mulheres e homens capazes de compreender holisticamente a ciência, considerando aspectos históricos e sociais, que reverberam em escolhas éticas e políticas (SANTOS; NUNES, 2016).

Santos e Mortimer (2002), em trabalho considerado canônico na área, apontam que o trabalho com a abordagem CTS em sala de aula é mais eficiente se melhor organizado e estruturado. As estruturas mais interessantes partem do problema social, discutem aspectos da tecnologia e da ciência envolvida no problema, e retornam para a discussão do problema apresentado inicialmente. Algumas atividades merecem destaque, como por exemplo palestras com expertos na área, demonstrações experimentais, rodas de debate, resolução de problemas jogos educativos e projetos, que podem direcionar reflexão e tomada consciente de decisão sobre ações e seus impactos (SILVA; AMARAL, 2013).

No presente trabalho o enfoque CTS é levado em consideração para a proposição de uma sequência didática para discutir conceitos químicos estruturantes, tais como elementos químicos, átomos, substâncias e suas propriedades, misturas, entre outros, buscando estabelecer um bloco de atividades para uma abordagem não tradicional de ensino.

As sequências didáticas, na perspectiva teórica apresentada por Méheut (2005), são utilizadas desde a década de 1970 como instrumento de ensino e pesquisa, e podem ser entendidas como o conjunto de atividades intrinsicamente relacionadas entre si, organizadas e planejadas para ensinar determinado conteúdo. Para a autora, existem o cerne da ideia de sequência didática está na existência de quatro componentes que irão direcionar os caminhos para sua elaboração, são eles: professor, aluno, mundo material e conhecimento científico. Esses componentes se relacionam em duas dimensões que permeiam toda a sequência: a dimensão epistemológica e a dimensão pedagógica, compondo, junto aos elementos centrais, o losango didático que descreve as relações existentes em uma sequência didática, apresentado na figura 1 :

Figura 1: Losango didático que descreve as relações em uma sequência didática. 


\section{Educação Química}
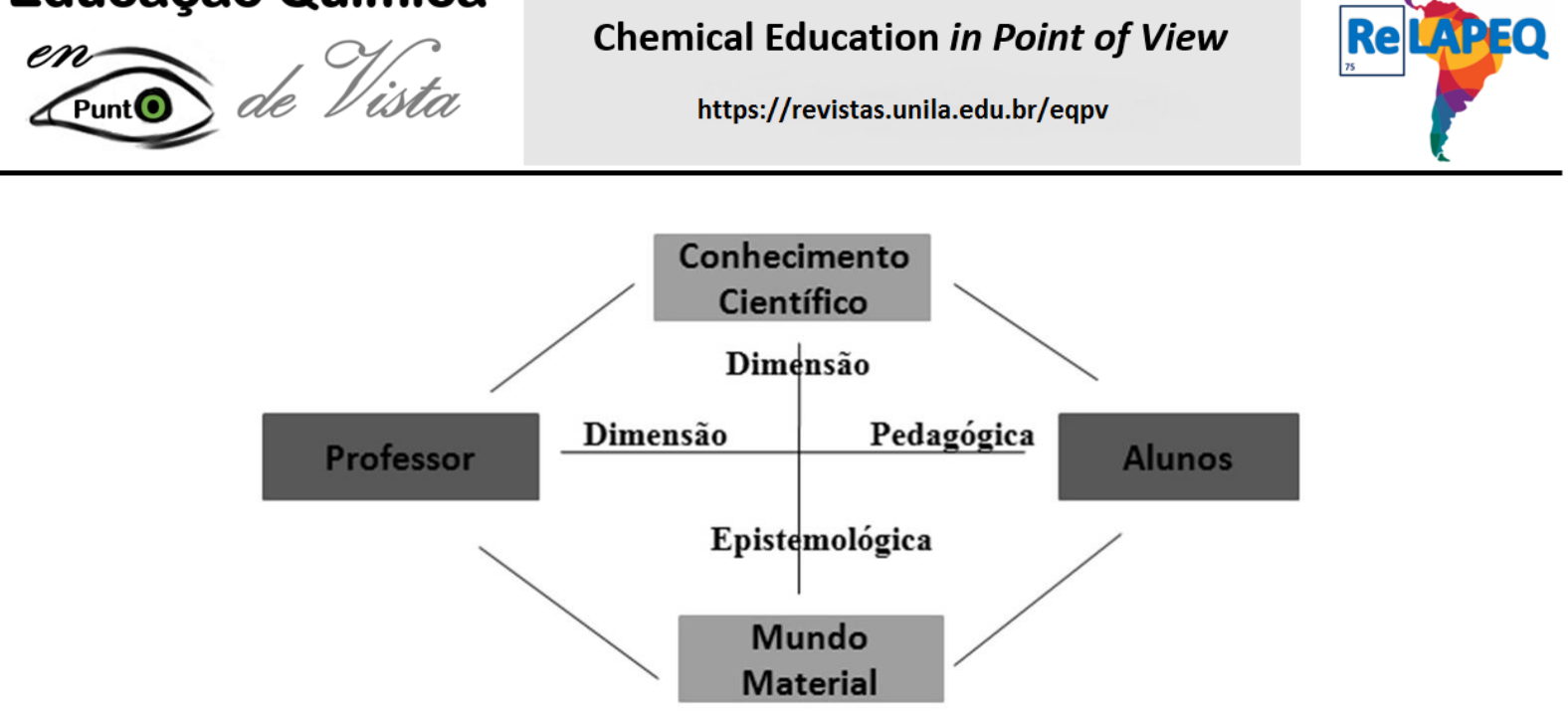

Fonte: Mourato e Simões Neto (2015).

A análise dos conteúdos a que deverão ser ensinados e os possíveis problemas que eles podem ajudar a responder são tratados pela dimensão epistemológica, que considera os processos de elaboração, escolha dos métodos e validação do conhecimento científico, relacionados com o mundo material. Já a dimensão pedagógica observa as relações que se estabelecem entre o professor e seus alunos, bem como entre os alunos, no funcionamento das relações de ensino, em situações que apresentam sempre uma intencionalidade didática.

Uma importante questão relacionada ao trabalho com sequências didáticas é a validação, que segundo Méheut (2005) pode ser realizada de duas formas, a saber: externa ou comparativa e a interna, que são complementares entre si. A validação externa é realizada com o objetivo de comparar os resultados de aprendizagem da sequência com os resultados obtidos mediante o ensino tradicional. Já a validação interna está relacionada com os objetivos considerados pelo professor, durante os momentos de desenho e elaboração da sequência, e os resultados obtidos, porém, mediante acompanhamento constante do processo. Podemos observar a validação, ou ao menos indícios de validação, de uma sequência didática a partir da comparação entre seus efeitos reais e os resultados esperados no seu planejamento (NASCIMENTO; GUIMARÃES; EL-HANI, 2009).

Nesse trabalho, buscamos propor o desenho de uma sequência didática para abordagem do tema lixo eletrônico no Ensino Médio. Discutiremos a seguir as metodologias para desenho e elaboração da sequência e, posteriormente, da sua aplicação em sala de aula.

\section{METODOLOGIA}

A metodologia desse trabalho está dividida em duas partes: a primeira versa sobre a elaboração da Sequência Didática, elemento central dessa proposta, e a segunda foca na 


\section{Educação Química}

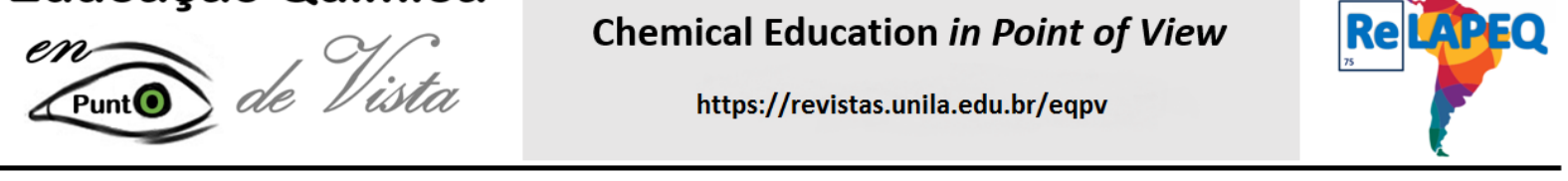

aplicação experimental da referida sequência, buscando estabelecer condições para validação da proposta.

\section{Elaboração da Sequência Didática}

A sequência didática foi elaborada pensando nas recomendações de Méheut (2005), considerando o losango didático, os elementos constituintes e as dimensões epistêmica e pedagógica. Assim, definimos inicialmente o tema Lixo Eletrônico, que pode ser entendido como um tema sociocientífico, bem como os conceitos químicos que poderiam ser discutidos na abordagem, os quais chamamos de conceitos estruturantes da química: elemento químico, átomos, moléculas, substâncias e misturas, numa perspectiva de visão contextual, ou seja, para além de definições e classificações, mas buscando sempre a relação com o mundo material. Dessa maneira o público-alvo definido foi estudantes do Ensino Médio, sem nenhuma preferência por alguma série específica.

Após a definição de tema, conceitos e público-alvo, buscamos elaborar as atividades da sequência, a partir da valorização da dimensão pedagógica, buscando atividades que coloquem o diálogo do entre professor e seus alunos, e entre os alunos, como elemento sempre presente, bem como estabelecendo situações nas quais os estudantes devem construir conhecimento, não só conceitual, mas também procedimental e atitudinal (POZO; GOMÉZ-CRESPO, 2009). Ainda, valorizamos a dimensão epistêmica, buscando nas atividades fazer com que os estudantes percebam as relações entre os conceitos químicos estruturantes e suas experiências no mundo material. Ambos direcionamentos nos parecem fundamentais para desenvolver o pensamento crítico e a tomada de decisão nos estudantes, sobretudo diante de problemas enfrentados em relação ao uso de tecnologias.

Desenhamos a sequência em cinco momentos, nos quais três deles $(1,2$ e 3$)$ têm duração de 50 minutos ( 1 aula cada) e outros dois (4 e 5) têm duração de 100 minutos (2 aulas geminadas).

\section{Aplicação da Sequência Didática}

A aplicação experimental da sequência didática, realizada para fins de validação inicial do desenho proposto, foi realizada com estudantes de uma turma do segundo ano do Ensino Médio do Colégio Agrícola Dom Agostinho Ikas, conhecido como CODAl e administrado pela Universidade Federal Rural de Pernambuco, como atividade extra desenvolvida por uma bolsista do Programa Institucional de Bolsas de Iniciação à Docência (PIBID). A escolha por trabalhar com uma turma do Segundo Ano foi pontual, uma vez que estávamos no início do ano letivo, tais conceitos ainda não estavam sendo trabalhados na turma do Primeiro Ano, além de poderem ser considerados estruturantes do pensamento 


\section{Educação Química}

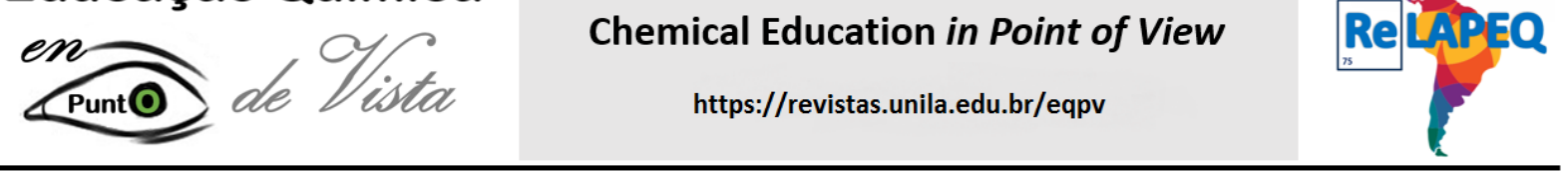

químico e essenciais para a compreensão da Físico-Química, conteúdo predominante nas discussões na turma durante todo o ano letivo.

É importante pontuar que a aplicação ocorreu em contra turno, no horário da tarde, como atividade adicional, atraindo a atenção de dez estudantes, que foram divididos em dois grupos de três e um grupo de quatro participantes, para a realização das atividades previstas na sequência, apresentadas e discutidas no próximo tópico.

Toda a intervenção visando a validação da sequência didática proposta foi gravada em áudio e vídeo, buscando: (i) registrar as interações entre estudantes e a professora e as interações dos estudantes entre si, nos grupos reduzidos e no grande grupo, buscando analisar as potencialidades da sequência didática em relação a dimensão pedagógica; (ii) registrar as relações estabelecidas pelos estudantes entre o conhecimento científico e tecnológico apresentado e o mundo material, ou seja, a sociedade e o meio ambiente, para observar a dimensão epistêmica.

Além das gravações, todo o material elaborado pelos estudantes na aplicação da sequência didática foi utilizado para análise acerca da validação, uma vez que as atividades propostas devem ter o potencial de dirigir a aprendizagem dos estudantes para a construção dos conhecimentos e relações associadas ao objetivo da sequência didática. Esses produtos foram analisados com foco entre as expectativas em relação as atividades e os resultados experimentais obtidos, conforme a ideia de validação apresentada por Méheut (2005).

\section{RESULTADOS E DISCUSSÃO}

Apresentaremos inicialmente os resultados e discussão para o desenho e elaboração da Sequência Didática. A seguir, buscando elementos para validação da proposta, realizamos a descrição da aplicação experimental da proposta em uma turma do segundo ano do Ensino Médio.

\section{Sequência Didática: "Lixo eletrônico e suas implicações sociais e ambientais"}

Conforme exposto na metodologia, a sequência foi desenhada considerando aspectos teóricos e metodológicos da proposta de Méheut (2005), considerando os elementos e dimensões apresentados no losango didático, em cinco momentos, os quais apresentamos a seguir:

Primeiro Momento: Apresentando o problema social e ambiental - o lixo eletrônico

Para iniciar a discussão sobre nossa temática, o lixo eletrônico, considerado como um problema social e ambiental, a atividade consiste em utilizar um recurso visual de 


\section{Educação Química}
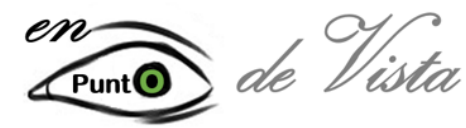

Chemical Education in Point of View

https://revistas.unila.edu.br/eqpv

impacto, uma charge, de autoria de Gilmar, superficialmente modificada para evidenciar o lixo eletrônico especificamente como foco da discussão.

A escolha por trabalhar com esse recurso não é arbitrária, uma vez que Charges são entendidas como parte de uma linguagem visual e que, de acordo com Martins, Golvêa e Piccinini (2005), é potencialmente expressa em um sistema de representação simbólica e influenciado por significados reconhecidos em determinada cultura, se constituindo como um importante recurso para a comunicação de ideias científicas. Ou seja, ao observar a imagem, em contexto de trabalho em sala de aula, alguns elementos podem ser reconhecidos pelos estudantes, possibilitando o sucesso da atividade elaborada.

As imagens, sobretudo em contextos de aplicação em processos de ensino e de aprendizagem, podem ser entendidas como representação visual ou analógica de um ser, fenômeno ou objeto, relacionado ao texto de maneira opositiva, buscando complementação (GIBIN; FERREIRA, 2013). Para Costa (2005), as imagens apresentam caráter mais intuitivo que a linguagem verbal ou escrita, pois são universais e, por isso, podem facilitar a aprendizagem dos estudantes.

Desta forma, o primeiro momento da sequência didática busca dar início a discussão sobre o lixo eletrônico a partir da apresentação e discussão sobre a charge anteriormente citada, apresentada na figura 2 , com destaque para suas implicações sociais e ambientais.

Figura 2: Charge utilizada no primeiro momento da sequência.

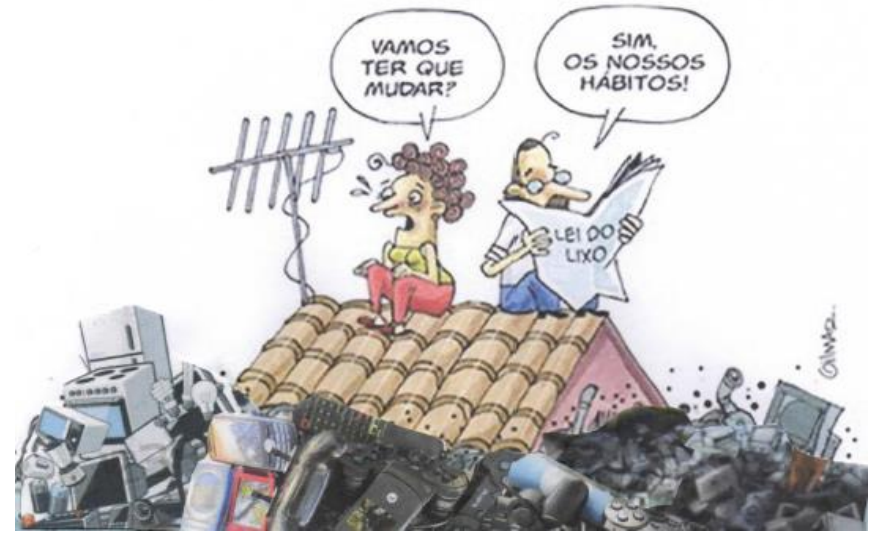

Fonte: Adaptada de www.humorpolitico.com.br.

Segundo Momento: Buscando concepções prévias - a construção de infográficos

O segundo momento tem como objetivo levantar as concepções prévias dos estudantes sobre o tema lixo eletrônico e potenciais soluções para os problemas de descarte, acúmulo e reciclagem. Assim, consideramos a divisão em grupos proposta aos 


\section{Educação Química}

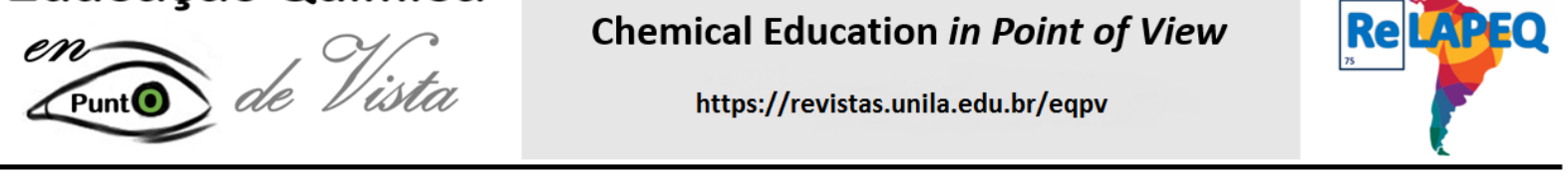

estudantes no primeiro momento para que discutam esses problemas a partir de suas experiências anteriores, visando a posterior proposição de um infográfico.

Segundo Costa e Tarouco (2010) os infográficos são importantes elementos na área da comunicação de informações, mas ainda pouco explorados em contextos de ensino, apesar de potencialmente interessantes. Constituem uma forma de apresentar de maneira eficaz informações sobre determinado tema, tornando a leitura mais interessante por incorporar meios semióticos distintos, como imagem e palavras (CALIGARI; PERFEITO, 2013). Assim, compreendemos infográficos como representações visuais de informações.

Para essa atividade cada grupo deve ser designado para a construção de um infográfico sobre o tema, a partir dos seus conhecimentos prévios, já construídos até o momento, sobre o tema, para exposição em um momento final de socialização. A produção de infográficos é uma habilidade adicional a ser desenvolvida nessa sequência didática. Dependendo da disponibilidade, os infográficos poderão ser construídos pelos estudantes utilizando computador ou, caso não seja possível a utilização da tecnologia, poderão utilizar materiais de escritório: papel, canetas hidrográficas, tesoura, cola, entre outros.

\section{Terceiro Momento: Problematizando os aspectos científicos e tecnológicos}

Para Simões Neto, Campos e Marcelino-Jr. (2013) a estratégia de resolução de problemas no ensino das ciências coloca o aluno como sujeito ativo de sua aprendizagem, possibilitando, a partir da superação de um obstáculo, à aprendizagem de conhecimentos científicos. No entanto, precisamos diferenciar duas propostas distintas e que podem ser confundidas: exercícios e problemas. O primeiro, que encontramos com frequência nos livros didáticos, apresenta resolução direta e pouco ampla, baseada em memorização ou aplicação de fórmulas, sendo sua característica principal a automação. Já problema pode ser entendido como uma:

\footnotetext{
Situação que um sujeito ou um grupo quer ou precisa resolver e para a qual não dispõe de um caminho rápido e direto que leve à solução. Seguindo esse conceito, uma situação somente pode ser concebida como um problema na medida em que os sujeitos atribuam um reconhecimento dela como tal, e quando requer dos que a tentam resolver um processo de reflexão ou uma tomada de decisão sobre a estratégia a ser seguida no processo de resolução de problemas. Um problema é uma situação nova ou diferente do que já foi aprendido, que requer a busca de estratégias ou de conhecimentos, ou de técnicas, ou ambos, para encontrar sua solução (BATINGA; TEIXEIRA, 2014, p.25).
}

Investindo na resolução de um problema, os estudantes vivenciam processos característicos da atividade científica, a saber: observação, reflexão, ação e tomada de decisão, que contribuem para a percepção da natureza sociocultural do conhecimento 


\section{Educação Química}
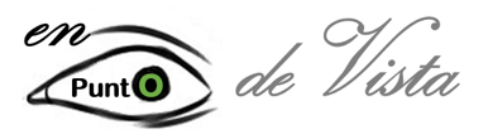

Chemical Education in Point of View

https://revistas.unila.edu.br/eqpv

científico (AZEVEDO, 2010). Desta forma, a resolução de um primeiro problema pelos grupos de trabalho é a atividade principal deste momento. O problema elaborado tem como temática o descarte de resíduos eletrônicos e pode ser observado no quadro 1 a seguir:

Quadro 1: Primeiro problema, relativo ao terceiro momento da sequência didática.

Em 2010 foi aprovada a lei federal no 12.305/2010, referente à política nacional de resíduos sólidos no Brasil, na qual se estabelece a obrigação em destinar de maneira adequada os resíduos eletroeletrônicos. Essa lei foi elaborada com o intuito de ensinar e alertar a população sobre os riscos trazidos por estes tipos de resíduos. Levando em consideração os aspectos químicos, quais são os riscos apresentados por esse tipo de lixo? Como fazer para minimizar os efeitos ambientais no descarte?

Fonte: Elaborado pelos autores.

Quarto Momento: Apresentando os conceitos estruturantes da Química

Os conceitos estruturantes da química deverão ser apresentados nesse quarto momento em uma aula expositiva dialogada, valorizando a linguagem científica, utilizando o quadro negro ou projetor multimídia, buscando sempre a participação dos estudantes durante a apresentação dos conceitos, para estabelecer interações entre os estudantes e com o professor. Ao final da apresentação das definições e exemplos, ainda, deverá ser apresentado o quadro 2, que informa ocorrência e danos causados por diversas substâncias encontradas no lixo eletrônico.

Quadro 2: Principais substâncias encontradas no lixo eletrônico.

\begin{tabular}{|c|l|l|}
\hline Substância & \multicolumn{1}{|c|}{ Onde é encontrado } & \multicolumn{1}{c|}{ Danos causados } \\
\hline Chumbo & $\begin{array}{l}\text { Computadores, celulares e } \\
\text { televisões. }\end{array}$ & $\begin{array}{l}\text { Danos aos sistemas nervoso e } \\
\text { sanguíneo. }\end{array}$ \\
\hline Mercúrio & $\begin{array}{l}\text { Computadores, monitores e } \\
\text { televisões de tela plana. }\end{array}$ & Danos cerebrais e ao fígado. \\
\hline Cádmio & $\begin{array}{l}\text { Computadores, monitores antigos } \\
\text { e baterias de notebooks. }\end{array}$ & $\begin{array}{l}\text { Envenenamento, danos aos ossos, rins } \\
\text { e pulmões. }\end{array}$ \\
\hline Arsênio & Celulares. & $\begin{array}{l}\text { Doenças de pele, prejudica o sistema } \\
\text { nervoso e pode causar câncer no } \\
\text { pulmão. }\end{array}$ \\
\hline Berílio & Computadores e celulares. & Câncer no pulmão. \\
\hline BRT & $\begin{array}{l}\text { Diversos componentes eletrônicos } \\
\text { para prevenção de incêndios. }\end{array}$ & $\begin{array}{l}\text { Desordens hormonais, nervosas e } \\
\text { pulmonares. }\end{array}$ \\
\hline PVC & Fios, para isolamento elétrico. & Se queimado e inalado, pode causar \\
\hline
\end{tabular}




\section{Educação Química}

\begin{tabular}{|c|l|l|}
\hline & $\begin{array}{l}\text { Chemical Education in Point of View } \\
\text { https://revistas.unila.edu.br/eqpv }\end{array}$ \\
\hline \multirow{2}{*}{ Lítio } & Pilhas e baterias. & $\begin{array}{l}\text { Afeta o sistema nervoso central, } \\
\text { gerando visão turva, ruídos nos } \\
\text { ouvidos, vertigens, debilidade e } \\
\text { tremores. }\end{array}$ \\
\hline \multirow{2}{*}{ Níquel } & Pilhas e baterias. & $\begin{array}{l}\text { Dermatites, distúrbios respiratórios, } \\
\text { gengivites, efeitos carcinogênicos, } \\
\text { cirrose e insuficiência renal. }\end{array}$ \\
\hline
\end{tabular}

Fonte: Adaptada do sítio brasileiro do Greenpeace - www.greenpeace.org/brasil.

Após a explicação do conteúdo e a apresentação da tabela, os alunos deverão formar novamente os grupos de trabalho e realizar a leitura dinâmica da cartilha do instituto Claro

(disponível em:https://www.institutoclaro.org.br/banco arquivos/cartilha_lixo eletronico.pdf), que fala sobre a temática do lixo eletrônico. O professor deverá ter a preocupação de garantir que todos os grupos participem ativamente das discussões e reflexões.

Neste momento podemos observar novamente aspectos da ciência quando abordamos e conceituamos cientificamente elementos e substâncias químicas, aspectos sociais quando relacionamos presença e possíveis problemas de saúde e os danos causados ao meio ambiente.

\section{Quinto Momento: Nova problematização do Lixo Eletrônico}

No quinto momento um segundo problema deverá ser apresentado aos alunos. Neste novo problema a temática abordada é a "obsolescência das tecnologias e suas implicações sociais e ambientais. ". Em relação a organização da sala de aula nesse momento, os estudantes deverão continuar em seus grupos de trabalho para realizar as discussões sobre o problema proposto, apresentado no quadro 3:

Quadro 3: Segundo problema, relativo ao quinto momento da sequência didática.

A tecnologia avança a uma velocidade cada vez maior! Todos os anos vários novos modelos de celulares, computadores e televisões são colocados no mercado e, desta forma, fazem com que a palavra obsolescência seja cada vez mais ouvida no nosso cotidiano. Segundo o dicionário Aurélio, obsolescência significa: (I) desclassificação tecnológico do material industrial, motivada pela aparição de um material mais moderno; (II) Redução gradativa e consequente desaparecimento. Na literatura encontramos três tipos de obsolescência, são elas: (A) Tecnológica: a melhoria tecnológica leva a substituição de um bem por outro; (B) Percebida: causada pela mudança de um valor social do objeto levando o consumidor a trocar seu bem, mesmo que não esteja no fim da vida útil, por um mais novo ou melhor; (C) 


\section{Educação Química}
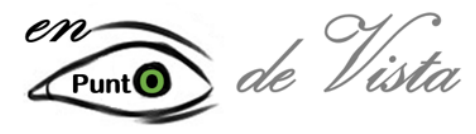

Chemical Education in Point of View

https://revistas.unila.edu.br/eqpv

Programada: resume como a indústria utiliza a tecnologia para regular a vida útil de seus objetos. Com base nas discussões feitas nas aulas anteriores e seus conhecimentos, e considerando os aspectos químicos, responda:

1. Que tipo de obsolescência cada figura ao lado aborda? Justifique.

2. Quais as consequências da obsolescência acelerada em relação a aspectos científicos (químicos), tecnológicos, sociais e ambientais?

3. Proponha soluções para esse problema que mobilizem consumidores, vendedores e produtores. No que a ciência (química) poderia ajudar?

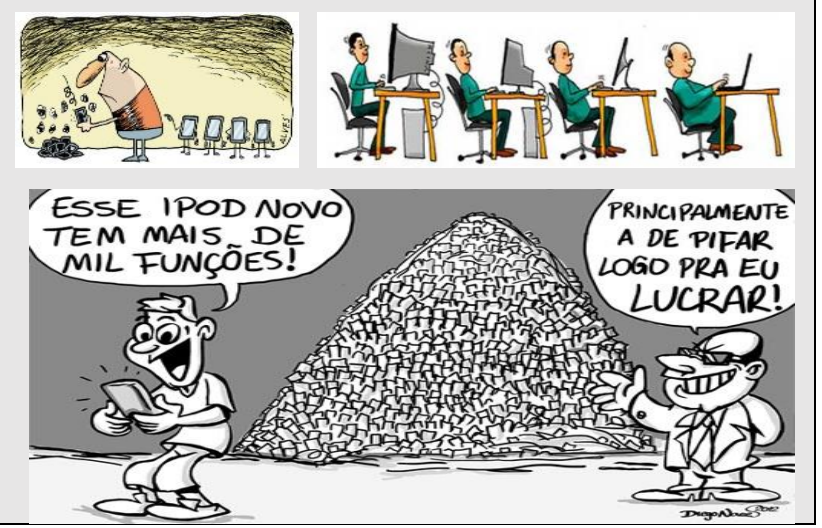

Fonte: Elaborado pelos autores.

Em seguida, as propostas e possíveis soluções apresentadas ao problema deverão ser socializadas a partir de apresentações curtas, entre dez e quinze minutos, conectadas com um debate sobre a obsolescência, contexto do problema.

Apresentado o desenho elaborado para a sequência didática, discutiremos a seguir os resultados de uma aplicação experimental na turma descrita na metodologia, em busca de elementos que possibilitem inferir acerca da validação da sequência didática proposta.

\section{Aplicação Experimental da Sequência Didática: Em busca da validação da proposta}

Buscando ter indícios sobre a validação da sequência didática proposta, fizemos uma aplicação experimental em uma turma do Segundo Ano do Ensino Médio do Colégio Agrícola Dom Agostinho Ikas (CODAI), conforme descrito na metodologia. Vamos analisar os resultados para cada um do momento da sequência didática proposta. A regência da sala de aula, durante a aplicação experimental, ficou aos cuidados de uma das pesquisadoras, que chamaremos de professora.

\section{Primeiro Momento}

Logo no início do primeiro momento a pesquisadora responsável pela regência apresentou aos estudantes a sequência didática, informando que seria uma proposta para abordagem de conteúdos da química vistos por eles no Primeiro Ano do Ensino Médio, mas sem informar que se tratavam dos conceitos por nós denominados de estruturantes. 


\section{Educação Química}

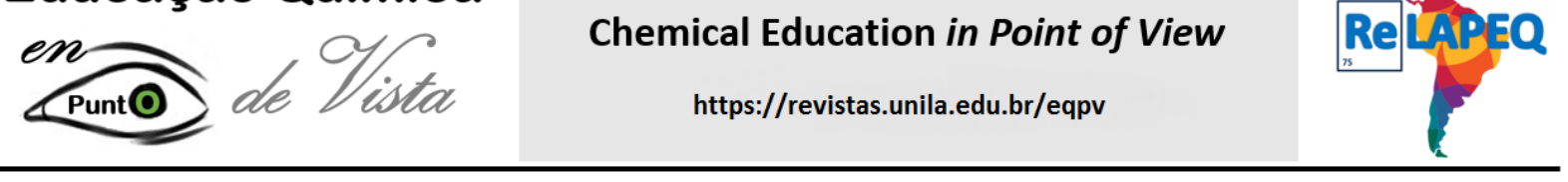

Em seguida a professora projetou no quadro a Charge (figura 1) e, após um tempo de observação, foram questionados sobre o tipo de lixo tratado na imagem. Todos os estudantes reconheceram se tratar de lixo eletrônico, à medida que iam reconhecendo os equipamentos eletrônicos e eletroeletrônicos na imagem.

Ao serem questionados sobre a natureza do lixo eletrônico, alguns associaram ao lixo relacionado com elétron ou o lixo que apresentava alguns elementos químicos específicos, como metais, evidenciando a relação com o conhecimento químico, embora uma relação ainda insipiente, talvez ativada pela presença da professora, bolsista do programa PIBID-Química. Um estudante citou o gás carbônico $\left(\mathrm{CO}_{2}\right)$ e a água $\left(\mathrm{H}_{2} \mathrm{O}\right)$ como elementos químicos. Podemos perceber uma confusão entre os conceitos estruturantes de átomos, substâncias e elementos químicos, que pode ser minimizada a partir de uma abordagem mais contextualizada com o mundo material, um dos objetivos associados a proposta.

Outra pergunta dirigida aos alunos versava sobre as consequências do descarte exagerado de lixo eletrônico. Os alunos reconheceram que tal forma de lixo pode poluir o meio ambiente e pode trazer problemas à saúde humana, pois podemos encontrar substâncias tóxicas, porém, não citaram nominalmente nenhuma delas.

Avaliamos, depois da aplicação do primeiro momento da sequência didática, que o objetivo de apresentar o lixo eletrônico como problema social e ambiental foi atingido, mesmo com respostas mais genéricas e pouco estruturadas dos alunos.

\section{Segundo Momento}

O principal objetivo do segundo momento da sequência didática era, por meio da elaboração de infográficos, realizar o levantamento das concepções prévias dos estudantes sobre o tema lixo eletrônico e, eventualmente, sobre os conceitos estruturantes, colocados como conhecimento científico da proposta. Os infográficos foram elaborados com material de papelaria, ou materiais de escritório, pela impossibilidade de utilizar computadores durante a aplicação experimental da sequência. Ao final do segundo momento os grupos apresentaram para os demais estudantes os seus infográficos.

No infográfico do grupo 1 os estudantes começam a ter uma compreensão sobre quais são os componentes do lixo eletrônico. Isso pode ser evidenciado no seguinte trecho do texto produzido para o infográfico: "O que é lixo eletrônico? Eletrodomésticos, bem como geladeiras, fogões, micro-ondas, etc. Baterias e pilhas onde fica armazenada a energia do aparelho". Os elementos gráficos ficaram em segundo plano, com o infográfico apresentado estando mais próximo de um fluxograma.

Também percebemos, no infográfico do grupo 1, indícios de associação entre 0 problema do lixo eletrônico e os conhecimentos químicos, destacando aspectos relacionados à saúde: "Esse tipo de lixo não pode ser reciclado. A maioria desse lixo possuí 


\section{Educação Química}
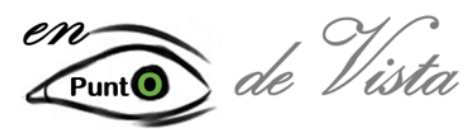

\section{Chemical Education in Point of View}

https://revistas.unila.edu.br/eqpv

materiais químicos que são tóxicos para o ser humano. [...] $O$ e-lixo libera gases que chegarão na camada de Ozônio". Ainda em relação ao trecho, podemos observar que os alunos não sabem que os materiais eletrônicos podem e devem ser reciclados. Um dos fatores que podem ter levado os participantes a esse tipo de afirmação é a falta de divulgação sobre a reciclagem ou reutilização desses materiais.

Apresentamos o infográfico desenvolvido pelo grupo 2, na figura 4, para ilustrar imageticamente o produto principal dessa discussão:

Figura 4: Infográfico elaborado pelo grupo 2.

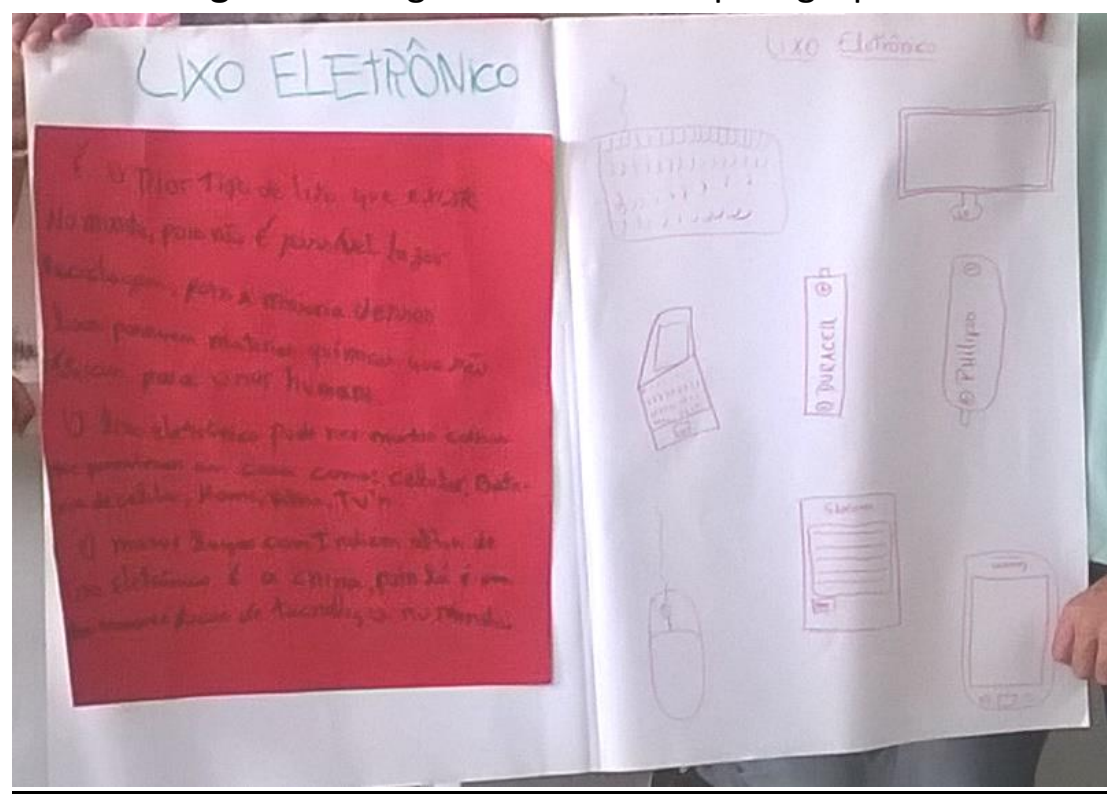

Fonte: Acervo dos autores.

O terceiro grupo não apresentou o infográfico. Assim como no primeiro momento, acreditamos que a construção dos infográficos, para os dois grupos que realizaram a atividade, cumpriu com seus objetivos: levantamento das concepções prévias sobre o lixo eletrônico, tema da sequência didática e associado ao mundo material, com eventuais relações com o conhecimento científico, os conceitos estruturantes.

\section{Terceiro Momento}

No terceiro momento, a resolução do primeiro problema, os estudantes estavam pouco concentrados e um pouco agitados. As respostas foram simples e diretas, mas serviram para iniciar um processo de conscientização social e ambiental em relação ao descarte correto dos eletrônicos e eletroeletrônicos. O quadro 4 apresenta as respostas dos três grupos: 


\section{Educação Química}

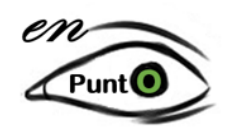

Quadro 4: Respostas dos grupos ao primeiro problema.

\begin{tabular}{|c|l|}
\hline Grupo & \multicolumn{1}{|c|}{ Resposta } \\
\hline 1 & $\begin{array}{l}\text { Esse tipo de lixo, o eletrônico, apresenta risco de poluir o solo e as águas o } \\
\text { descarte deve ser feito devolvendo ao fabricante. }\end{array}$ \\
\hline 2 & $\begin{array}{l}\text { O lixo eletrônico prejudica o meio ambiente e o descarte deve ser especial, } \\
\text { por empresas específicas. }\end{array}$ \\
\hline 3 & $\begin{array}{l}\text { Existe a possibilidade de pilhas e baterias serem devolvidas para os } \\
\text { fabricantes e com isso evitar a poluição eletrônica. }\end{array}$ \\
\hline
\end{tabular}

Fonte: Elaborado pelos autores.

Todos os grupos indicaram nas respostas os danos causados ao meio ambiente e a existência de empresas especializadas em coletar esse tipo de lixo.

\section{Quarto Momento}

O quarto momento tinha por objetivo a abordagem dos conceitos científicos e suas relações com o mundo material. A estratégia utilizada foi a aula expositiva dialogada, utilizando um computador com projetor multimídia. Avaliamos o momento como pouco proveitoso, pois o espaço destinado a participação dos estudantes ficou aquém do esperado, tornando o momento uma exposição simples de ideias pela professora.

Uma possível modificação na sequência didática, trazendo como atividade central desse momento um vídeo sobre lixo eletrônico e posterior debate, em substituição a aula expositiva dialogada, foi considerada na análise da aplicação experimental.

Em seguida a professora iniciou as discussões dos aspectos evidenciados pela cartilha Claro, apresentando as relações entre ciência, tecnologia e sociedade. No decorrer da leitura dinâmica deste material foram levantadas discussões sobre a quantidade e qualidade do lixo eletrônico produzido no Brasil e os alunos começaram a perceber que pouco é feito pelo poder público e pelos cidadãos, individualmente. Um dos estudantes comentou: "cada um tem que ter a consciência de onde joga o e-lixo".

Em outro momento da discussão, a professora inicia uma análise sobre os pontos de coleta que existem para o lixo eletrônico próximos as residências dos estudantes. $\mathrm{Na}$ cartilha, um dos pontos tratados é a "logística reversa", um conjunto de ações que facilitam o retorno dos resíduos a quem os produziu para que sejam reciclados. Uma das alternativas que a cartilha sugere para o descarte correto é que o consumidor entre em contato com o fabricante para que a indústria possa dar a destinação correta ao aparelho que não está sendo mais utilizado (isto se aplica aos eletroeletrônicos maiores, como geladeiras, fogões, televisores) ou levar em postos de coletas (no caso de celulares, computadores, baterias e 


\section{Educação Química}

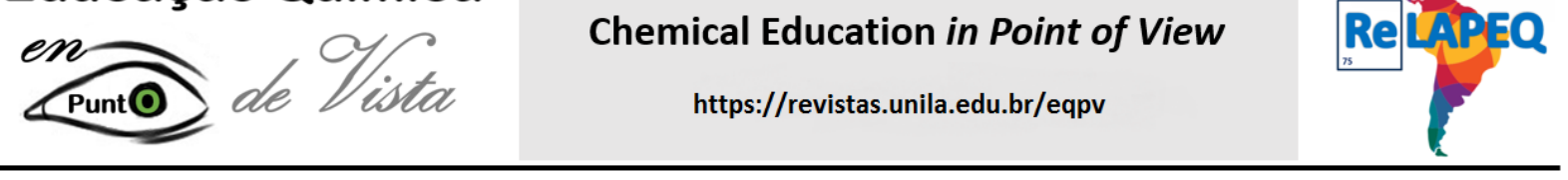

pilhas). Os alunos começam a refletir e reconhecer o problema do acúmulo de lixo eletrônico em lugares inadequados.

Sobre o terceiro e quarto momento, acreditamos que o trabalho de discussão com base na cartilha do instituto Claro foi deveras eficiente, porém, os estudantes não participaram ativamente das discussões na aula expositiva, bem como não investiram sobre a resolução do problema da forma esperada para que a atividade tivesse sucesso dentro dos objetivos da sequência didática.

\section{Quinto Momento}

Assim como no terceiro momento as respostas relativas ao segundo problema foram bastante superficiais. Os alunos não compreenderam bem o significado do conceito de obsolescência e não conseguiram diferenciar bem os três tipos que são citados no enunciado do problema. O único tipo de obsolescência que eles percebem de maneira correta é a tecnológica.

Em relação as outras duas questões postas no problema, não obtivemos respostas coerentes com o que foi proposto. Os alunos não conseguiram fazer conexões entre a obsolescência acelerada e os aspectos abordados nas discussões realizadas ao longo da sequência.

Como soluções para a obsolescência, foi sugerido que a instalação de mais totens do tipo papa-pilhas nos estabelecimentos e que as pessoas se conscientizassem em relação aos perigos que o lixo eletrônico proporciona, mas, além de não propor soluções mais detalhadas, os estudantes não conseguiram encontrar uma resolução que envolvesse os conceitos da química.

Acreditamos que alguns problemas de ordem organizacional e metodológica atrapalharam o desenvolvimento das respostas dos estudantes para o segundo problema, uma vez que os estudantes eram liberados ao final da atividade, o debate também não possibilitou discussões mais abrangentes sobre o tema. Assim, encontramos dificuldades nos dois momentos da sequência didática em que as atividades estavam relacionadas a resolução de problemas. Porém, acreditamos que os problemas não estão na atividade proposta, mas na metodologia de aplicação.

\section{CONSIDERAÇÕES FINAIS}

O desenho da sequência didática intitulada "Lixo eletrônico e suas implicações sociais e ambientais" foi pensado a partir dos aspectos teóricos apresentados por Méheut (2005), considerando os elementos centrais e as dimensões associadas ao losango didático. Assim, a sequência foi elaborada para cinco momentos, cada um com atividades que pudessem proporcionar a reflexão, aprendizagem, desenvolvimento de pensamento crítico e 


\section{Educação Química}

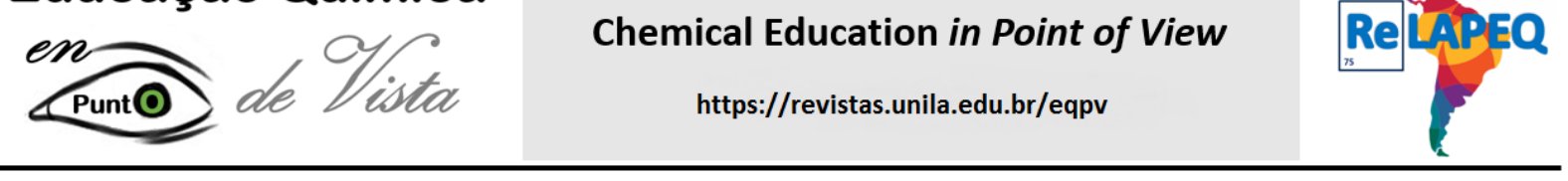

tomada de decisão para questões envolvendo consumo, descarte, reciclagem e/ou reutilização de materiais eletrônicos, utilizando aspectos da abordagem CTS, inclusive na estruturação das etapas, partindo do problema, apresentando os aspectos científicos e tecnológicos e voltando ao problema social e ambiental apresentado inicialmente.

Metodologias que utilizam a abordagem CTS são importantes na formação do cidadão crítico e consciente dos seus atos. Quando colocamos os alunos diante de temas como o tratado na sequência didática proposta, fica mais fácil realizar as conexões entre os conceitos científicos, que são aprendidos em sala de aula, e as experiências cotidianas, relacionadas ao mundo material. Além disso, podemos relacionar os conteúdos trazidos de uma maneira interdisciplinar, rompendo com a visão fragmentada da ciência.

A aplicação da sequência no piloto apresentou alguns problemas. O primeiro, de ordem organizacional, pois tivemos que propor uma atividade em contra turno, para uma turma de Segundo Ano do Ensino Médio, atraindo apenas dez estudantes. No entanto, os resultados obtidos para alguns dos momentos indicam as potencialidades da sequência em tela para o tratamento do tema lixo eletrônico. Os problemas foram pontuais, principalmente na resolução dos problemas, talvez ocasionado pela não atribuição de nota a atividade, e na participação na aula expositiva dialogada, muito aquém do esperado.

As atividades se mostraram bastante consistentes e interessantes, mesmo os problemas, que embora bem construídos, a aplicação não evidenciou os obstáculos para a resolução, permitindo respostas superficiais e evasivas.

Acreditamos que a sequência didática proposta responde bem a seus objetivos, trabalhar, em associação com a abordagem CTS, o tema lixo eletrônico para discutir conceitos estruturantes da química, além de trabalhar com atividades que exigem protagonismo do estudante, como resolução de problemas e construção de infográficos, o que contribui para a construção de conhecimentos conceituais, procedimentais e atitudinais, que vão reverberar na formação de cidadãos críticos, com capacidade de tomar decisões de maneira consciente.

A pesquisa que envolve a elaboração, proposição e aplicação de sequências didáticas tem um duplo objetivo que é inerente a proposta: trata-se de um instrumento de pesquisa e também de ensino. Assim, a presente pesquisa contribuí para a área de ensino de química tanto como na reflexão sobre atividades que, relacionadas ou não, podem contribuir para aprendizagem de conteúdos estruturantes da química, além de ajudar na formação do cidadão crítico, devido ao aspecto CTS, quanto auxilia os professores em exercício, mediante a proposta da sequência, que pode ser aplicada em suas salas de aula.

Por fim, percebemos que apesar dos problemas que foram identificados na aplicação experimental, as atividades propostas para a sequência didática em tela atende aos objetivos da abordagem CTS no ensino de ciências: reflexão entre a ciência, a tecnologia, a sociedade, as relações entre esses três elementos, a tomada de decisão, que direciona a 


\section{Educação Química}

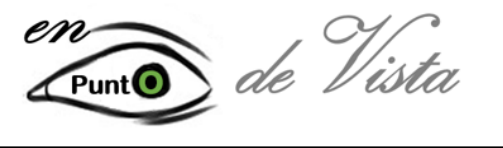

Chemical Education in Point of View

https://revistas.unila.edu.br/eqpv

uma participação ativa nas decisões da sociedade, buscando a alfabetização científica e tecnológica para exercer de maneira adequada a cidadania (SANTOS; MORTIMER, 2001). Outras propostas, tais como Firme e Amaral (2011) e Mourato e Simões Neto (2015), que também trabalham com sequências didáticas para abordar conteúdos da química, pilhas e baterias e petróleo, respectivamente, apresentam atividades com potencialidades e problemas semelhantes aos que observamos, e lograram sucesso ao atingir os objetivos de cada uma das pesquisas.

\section{Referências}

AZEVEDO, M. C. P. T. Ensino por investigação: problematizando as atividades em sala de aula. In: CARVALHO, A. M. P. (org.) Ensino de Ciências: unindo a pesquisa e a prática. São Paulo: Cengage Learning, p. 166, 2010.

BATINGA, V. T. S.; TEIXEIRA, F. M. A Abordagem de Resolução de Problemas por uma professora de Química: Análise de um problema sobre a Combustão do Álcool envolvendo o conteúdo de Estequiometria. Revista Brasileira de Ensino de Ciência e Tecnologia, v. 7, n. 1, p. 24-52, 2014.

CALIGARI, D. A.; PERFEITO, A. M. Infográfico: Possibilidades metodológicas em salas de aula de Ensino Médio. Entretextos, v.13, n. 1, p. 291-307, 2013.

COSTA, C. Educação, imagem e mídias. São Paulo: Cortez, 2005.

COSTA, Y. F.; SILVA, B. H. Polímeros: solução ou poluição? Uma abordagem CTS no ensino de química orgânica para o Ensino Médio. In: Jornada de Ensino, Pesquisa e Extensão da UFRPE, 13, 2013. Anais..., Recife-PE, p. 1-4, 2013.

COSTA, L. M.; TAROUCO, L. M. R. Infográfico: características, autoria e uso educacional. Novas Tecnologias na Educação, v. 8, n. 3, p. 1-14, 2010.

FAVERA, E. C. D. Lixo eletrônico e a sociedade. 2008. Disponível em: http://wwwusr.inf.ufsm.br/ favera/elc1020/t1/artigo-elc1020.pdf (acessado em 15/07/2017).

FIRME, R. N.; AMARAL, E. M. R. Analisando a implementação de uma abordagem CTS na sala de aula de química. Ciência \& Educação, v. 17, n. 2, p. 383-399, 2011.

GIBIN, G. B.; FERREIRA, L. H. Avaliação dos estudantes sobre o uso de imagens como recurso auxiliar no ensino de conceitos químicos. Química Nova na Escola, v.25, n. 1, p. 19-26, 2013.

MARTINS, I.; GOUVÊA, G.; PICCININI, C. L. Aprendendo com imagens. Ciência e Cultura, v. 57, n. 4, p. 38-40, 2005.

MÉHEUT, M. Teaching-learning sequences tools for learning and/or research. Paris: Springer, 2005. 


\section{Educação Química}
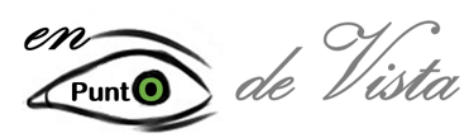

Chemical Education in Point of View

https://revistas.unila.edu.br/eqpv

MOURATO, E. R. G.; SIMÕES NETO, J. E. Uma sequência didática sobre petróleo e derivados para a construção de conceitos químicos na educação de jovens e adultos. Cadernos de estudos e pesquisa na educação básica, v. 1, n. 1, p. 78-97, 2015.

NASCIMENTO, L. M. M.; GUIMARÃES, M. D. M.; EL-HANI, C. N. Construção e validação de sequências didáticas para o ensino de biologia. In: Encontro Nacional de Pesquisa em Educação em Ciências, 7, 2009. Anais..., Florianópolis-SC, p. 1-12, 2009.

PARENTE, V. C. I. Contextualização do lixo eletrônico em aulas de química no Ensino Médio. Monografia, Graduação em Licenciatura em Química, Universidade de Brasília, Brasília, 2007.

POZO, J. I.; GOMÉZ-CRESPO, M. A. Aprendizagem e o ensino de ciências: do conhecimento cotidiano ao conhecimento científico. 5 ed. Porto Alegre: Artmed, 2009.

SANTOS, K. F.; NUNES, A. O. Desafios para a adoção do enfoque CTS em práticas pedagógicas da educação básica: as percepções dos professores. Revista Eletrônica Debates em Educação Científica e Tecnológica, v. 6. n. 1, p. 169-190, 2016.

SANTOS, W. L. P.; MORTIMER, E. F. Uma análise de pressupostos teóricos da abordagem C-T$S$ (ciência - tecnologia - sociedade) no contexto da educação brasileira. Ensaio: pesquisa em educação em ciências, v. 2, n.2, p. 1-23, 2002.

SANTOS, W. L. P.; SCHNETZLER, R. P. Educação em química: compromisso com a cidadania. 1 ed. Ijuí-RS: EdUnijuí. 1997.

SILVA, B. H.; AMARAL, E. M. R. Perspectiva CTS na formação inicial de professores de química: uma análise do planejamento para a ação docente. In: Encontro Nacional de Pesquisa em Educação em Ciências, 9, 2013. Anais..., Águas de Lindóia-SP, p. 1-8.

SIMÕES NETO, J. E.; CAMPOS, A. F.; MARCELINO-JR., C. A. C. Abordando a isomeria em compostos orgânicos e inorgânicos: uma atividade fundamentada no uso de situaçõesproblema na formação inicial de professores de química. Investigações em Ensino de Ciências, v. 18, n. 2, p. 327-346, 2013. 


\section{Educação Química}
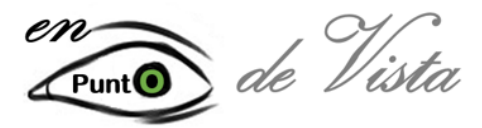

Chemical Education in Point of View

https://revistas.unila.edu.br/eqpv

\section{RESUMO}

O objetivo desse trabalho foi a proposição de uma sequência didática para abordagem do tema lixo eletrônico no Ensino Médio. Para isso estruturamos a sequência intitulada "Lixo eletrônico e suas implicações sociais e ambientais", em cinco momentos: apresentação do problema social, levantamento de concepções, apresentação dos conceitos químicos estruturantes a partir de uma aula expositiva dialogada e dois momentos para resolução de problemas, um centrado no descarte do lixo eletrônico e outro nas ideias de obsolescência e reciclagem. Buscamos a validação da proposta a partir da aplicação em uma turma do Segundo Ano do Ensino Médio de uma escola técnica federal, localizada em Camaragibe, Pernambuco. Os resultados apontam para a validação da proposta, com destaque para a sugestão de utilização de coleta seletiva de lixo e de papa-pilhas na escola, porém, os estudantes mostraram ter dificuldades em entender a ideia de obsolescência do lixo eletrônico.

\section{RESUMEN}

El objetivo de este trabajo fue la proposición de una secuencia didáctica para el abordaje del tema basura electrónica en la Enseñanza Media. Para ello estructuramos la secuencia titulada "Basura electrónica y sus implicaciones sociales y ambientales", en cinco momentos: presentación del problema social, levantamiento de concepciones, presentación de los conceptos químicos estructurantes a partir de una clase expositiva dialogada y dos momentos para la resolución de problemas, un centrado en el descarte de la basura electrónica y otro en las ideas de obsolescencia y reciclaje. Buscamos la validación de la propuesta a partir de la aplicación en una clase del segundo año de la enseñanza media de una escuela técnica federal, ubicada en Camaragibe, Pernambuco. Los resultados apuntan a la validación de la propuesta, con destaque para la sugerencia de utilización de colecta selectiva de basura y de papa-pilas en la escuela, sin embargo, los estudiantes mostraron tener dificultades para entender la idea de obsolescencia de la basura electrónica. 